\title{
Analysis of Progress Towards a Comprehensive System of Marine Protected Areas in Brazil
}

\author{
R. A. Magris ${ }^{1 *}$, M. Mills ${ }^{2}$, M. M. P. B. Fuentes ${ }^{1} \&$ R. L. Pressey ${ }^{1}$
}

\author{
${ }^{1}$ Australian Research Council Centre of Excellence for Coral Reef Studies, James Cook University - JCU, \\ Townsville, QLD, Australia \\ ${ }^{2}$ Global Change Institute, The University of Queensland - UQ, Brisbane, QLD, Australia
}

\begin{abstract}
Brazilian marine ecosystems face great threats while retaining outstanding biological features. A gap analysis was conducted to evaluate how well marine protected areas (MPAs) in Brazil meet conservation objectives for representation, connectivity, and risk-spreading. The performance of the MPAs was evaluated by overlaying maps of ecosystem and management and calculating the size of no-take areas and the distances between them. All objectives were far from fully attained. Currently, the protection of the marine environment is poor, with less than $1.9 \%$ of Brazil's marine jurisdiction within MPAs and $0.14 \%$ within no-take areas. Also, only $23 \%$ of the ecosystems met the minimal number of replicates required by the risk-spreading objective. More positively, just over half (51\%) of the no-take areas are a desirable distance apart. Our study highlights that a systematic expansion of MPAs in Brazil is urgently needed to move toward an ecologically representative and functioning MPA system.
\end{abstract}

Key words: Systematic Conservation Planning, Biodiversity Conservation, Marine Conservation, Gap Analysis, Effectiveness.

\section{Introduction}

Marine ecosystems are experiencing accelerating and alarming ecological degradation and loss of species, both of which impair the ocean's capacity to provide food, maintain water quality, and recover from perturbations (Worm et al. 2006). Declines of marine species and degradation of ecosystems have occurred primarily as a result of overharvesting, pollution, and the direct and indirect impacts of climate change (Halpern et al. 2008). Similar to the global situation, Brazilian marine ecosystems and species are subject to many anthropogenic threats, with coastal waters and estuaries adjacent to the Brazilian coast experiencing medium to medium-high impacts (Halpern et al. 2008, 2012).

The outstanding biological features of the Brazilian marine environment (e.g. Leão \& Dominguez 2000; see Appendix S1 for additional information), coupled with expanding and intensifying threats to marine biodiversity, highlight the need for conservation management and promotion of sustainable use of biodiversity. Important tools for both conservation and sustainable use are marine protected areas (MPAs). Protected areas are designated or regulated, and managed to achieve specific conservation objectives (CBD 2013). As a commitment to reducing declines in marine

\section{* Send correspondence to: Rafael Magris}

Australian Research Council Centre of Excellence for Coral

Reef Studies, James Cook University - UQ, Townsville, QLD, 4811, Australia

E-mail: rafael.magris@my.jcu.edu.au biodiversity, Brazil has signed and ratified the Convention on Biological Diversity (CBD). More recently, Brazil has agreed to achieve the Aichi Biodiversity Targets, with a goal of encompassing $10 \%$ of its seas and coastal areas within an effectively managed, ecologically representative and well connected system of MPAs by 2020 (CBD 2013). In addition, the Brazilian government committed to implement the National Protected Areas Plan, with the overall goal of consolidating a system of effectively managed and ecologically representative protected areas by 2015 (Brasil 2006). However, only a small portion (1.87\%) of Brazil's marine jurisdiction is currently under protection. Therefore, an increase of the MPA network in Brazil, systematically designed to maximize the benefits for biodiversity, is timely.

Systematic conservation planning provides a valuable framework for MPA network design, using quantitative objectives to guide the configuration of protected areas to promote the representation and persistence of biodiversity in situ (Pressey et al. 2007). Representation of species (biodiversity pattern) can be obtained by selecting protected areas that sample the biotic diversity of the marine ecosystems with which they are associated (Harris \& Whiteway 2009). Planning for persistence is less evolved (Pressey et al. 2007) because it requires that biodiversity processes are conserved, directs attention to dynamic threats, and demands more data than when planning for representation. To overcome the existing lack of data to plan for persistence, generic design 
criteria have been developed with the aim of minimizing impacts of threats to ecosystems, promoting connectivity between populations, and supporting other important processes (e.g Airamé et al. 2003; Fernandes et al. 2005; Green et al. 2009).

A key step in conservation planning is a gap analysis (Rodrigues et al. 2004; Spalding et al. 2008), in which the achievement by protected areas of quantitative objectives for representation and persistence is reviewed (Pressey et al. 2007). This helps identify areas, species and ecosystems that require further protection. To guide future ecologically effective expansion of MPAs in Brazil, we undertake a marine gap analysis to assess how well Brazil meets conservation objectives for representation and persistence.

\section{Material and Methods}

A gap analysis (Figure 1) was undertaken to determine how well conservation objectives were met by the existing MPAs in the entire oceanic area under Brazilian national jurisdiction (Exclusive Economic Zone - EEZ; $3,642,070 \mathrm{~km}^{2}$, Figure S1). Our gap analysis involved interpreting three principles - representation, connectivity, and risk spreading - into explicit conservation objectives and assessing the performance of the current system of marine protected areas in achieving these objectives (see Section Gap Analysis).

\section{Geographic Information System (GIS) layer compilation}

All available ecosystem and marine resource management maps were compiled (Figure 1A), using ArcGIS v10 software. Ecosystems included: coral reef, mangrove, and other substrata in six depth zones: 0-10 m, 10-25 m, 25-50 m, 50-75 m, 75-100 m, and >100 m). These were intersected with eight ecoregions - 1. Amazon; 2. Northeastern; 3. Eastern; 4. Fernando de Noronha and Atoll das Rocas; 5. São Pedro and São Paulo Islands; 6. Trindade and Martin Vaz Islands; 7. Southeastern Brazil; and 8. Rio Grande - to produce 56 ecosystems. Further details about our ecosystem map are in Appendix S1 and Figure S1. This was the best available national delineation of marine ecosystems. Other ecosystems could have been chosen in light of their biological relevance for marine species (e.g. rocky reef, seagrass), but their distributions were not available for the entire Brazilian marine jurisdiction at reasonable accuracy. Conservation assessment based on broad ecosystems (such as bioregions and depth classes) are often necessary due to lack of knowledge about the distributions of more finely subdivided ecosystems and their associated species (Lombard et al. 2007; Mills et al. 2011).

Information on location of MPAs in Brazil was gathered and compiled from datasets held by the Brazilian Ministry of Environment and other environmental organizations (e.g. http://www.mma.gov.br/areas-protegidas/ cadastro-nacional-de-ucs). This spatial dataset consisted of 142 MPAs under three levels of governance: federal, state, and municipal. We considered MPAs to be those areas with estuarine or oceanic biota, including all MPAs that intersected the upper intertidal zone (upper limit of occurrence of mangrove ecosystems). MPAs were placed into three broad categories with different forms of management intent: no-take areas, extractive reserves, and multiple-use areas. The main characteristics of each category are described in Appendix S1 (and see Figure S2). This was necessary because Brazilian MPAs embrace a wide range of management types (Brasil 2000). Our "management" dataset encompassed the legal boundaries of 56 no-take areas, 23 extractive reserves, and 63 multiple-use areas.

\section{Gap analysis}

Having compiled maps of ecosystems and MPA types, we conducted a gap analysis to assess the extent to which the conservation objectives for representation and persistence had been achieved (Figure 1B). Objectives for representation were percentages of each ecosystem type (Rondinini \& Chiozza 2010). Objectives for persistence (Pressey et al. 2007) related to connectivity and risk-spreading.

Our representation objectives were $30 \%$ coverage of each ecosystem within the MPA network and $20 \%$ coverage of each ecosystem within no-take areas. These objectives can be refined according to various criteria (e.g. Pressey et al. 2003) and should be seen by conservation practitioners as temporary measures whilst objective-setting based on species-area relationships (Metcalfe et al. 2013), rarity, threats and other criteria is underway. The $30 \%$ target is the "[...] average percentage of protected area recommended as necessary to conserve various aspects of biodiversity [...]" for evidence-based conservation assessments (Svancara et al. 2005, p. 991). Our no-take area target is based on studies suggesting that, for fisheries management and to prevent major loss of species richness, no-take areas need to cover at least $20 \%$ of the extent of each marine ecosystem (Fernandes et al. 2005; Beck \& Odaya 2001). Although the Brazilian Government has committed to achieving the Aichi Biodiversity Targets, we decided that our representation objective should not be constrained by the Aichi percentage of $10 \%$, which is a policy-driven target without consideration of ecological requirements (Svancara et al. 2005).

For connectivity, we stipulated that a single no-take area should have a minimum size of $10 \mathrm{~km}^{2}$ and the distance between adjacent no-take areas should not exceed $15 \mathrm{~km}$ (Halpern \& Warner 2003; Shanks et al. 2003; Green et al. 2009). We focused on these aspects of design because they are often suggested as critical considerations to maintain connectivity between populations (Roberts et al. 2003). Our application of size and spacing thresholds only to no-take areas was intended to ensure strong connectivity given uncertainty around the effectiveness of extractive reserves and multiple-use areas for biodiversity conservation 


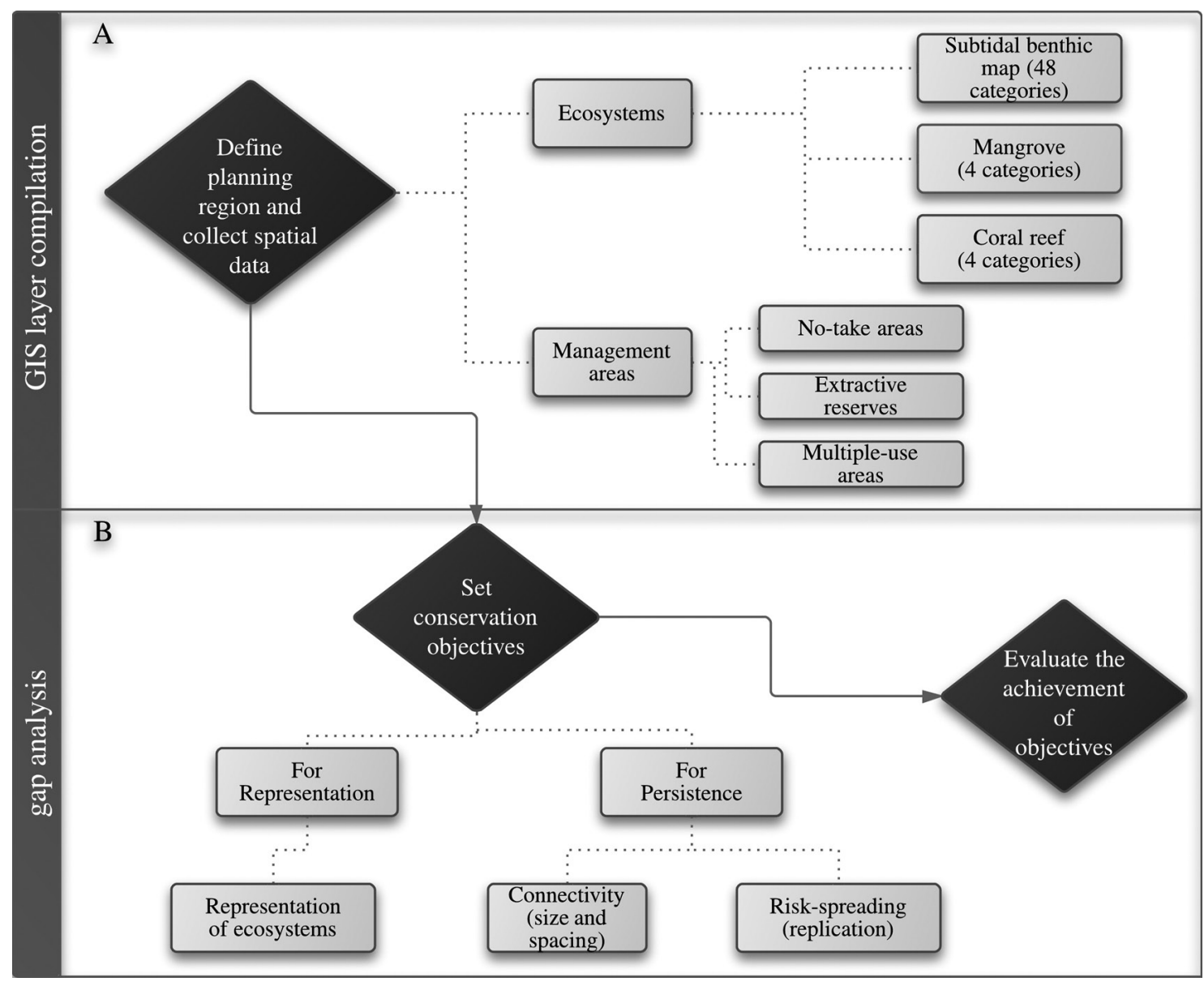

Figure 1. Schematic flowchart depicting all steps in the methods for this paper, including the two broad phases: GIS layer compilation (A) and gap analysis (B). The main groups of steps are indicated by dark diamonds. Light boxes show steps and types of data or objectives extracted or derived.

and the desirable configuration of these other MPA types (CBD 2013). Our rules of thumb for connectivity can also be refined when more information is available on larval dispersal (Almany et al. 2009) and adult movements (Kramer \& Chapman 1999) for species of interest.

Our risk-spreading objective was at least 3 examples of each ecosystem type in the same ecoregion in different no-take areas (Green et al. 2009). Replication of conservation features across multiple no-take areas lessens the probability that a catastrophic event (e.g. oil spill, mass bleaching) within a no-take area will eliminate entire protected populations of species (Airamé et al. 2003; Roberts et al. 2003). Objectives for risk-spreading took into account only no-take areas as a precautionary approach. Data to measure the susceptibility to disturbances of species and ecosystems, combined with effects of extractive uses, are unavailable for extractive reserves and multiple-use areas. These objectives can be refined for subsequent gap analyses with information on the spatial and temporal patterns of disturbances (Allison et al. 2003; Ban et al. 2012), species responses, and recovery rates in different kinds of MPAs.
The ecosystem map was overlaid with a data layer containing management area boundaries to identify gaps in coverage and quantify the extent to which representativeness and risk-spreading objectives had been achieved by the existing MPAs. Wherever MPA boundaries overlapped, we recognized the most restrictive management category (no-take area > extractive reserve $>$ multiple-use areas). For connectivity, we calculated the size of each single no-take MPA and the Euclidean distance between nearest pairs of centroids of no-take MPAs. If no-take areas contained spatially separate sections, we examined each polygon individually (56 no-take areas resulted in 91 individual polygons). All analyses were performed using ArcGIS v10.

\section{Results}

\section{Representation}

MPAs covered 192,343 $\mathrm{km}^{2}$ (1.87\%) of the waters within the Brazilian EEZ, although only $0.14 \%$ was within no-take areas. The representation objectives were far from being fully attained. Most (>85\%) of the ecosystems fell short 
of having $20 \%$ coverage by no-take areas (Figure 2), with median coverage by no-takes at $0.01 \%$ (mean coverage of $11 \%)$. There were also substantial shortfalls in achieving the $30 \%$ objective for coverage by all MPA categories. Only $26 \%$ of ecosystems met this objective (Figure 2) with median coverage by all MPAs at $1.31 \%$ (mean coverage of $21 \%$ ).

Twenty-five percent of ecosystems had no coverage by all MPAs combined, and $50 \%$ had no coverage by no-take areas. Only coral reefs and ecosystems in one ecoregion (Fernando de Noronha and Atoll das Rocas) were adequately protected according to our objectives. Under-protected ecosystems were distributed throughout the Brazilian EEZ but protection was consistently poor for ecosystems deeper than 100m, the oceanic ecoregions São Pedro and São Paulo Islands and Trindade and Martin Vaz Islands, and the Rio Grande ecoregion. Although mangroves in Amazon, Eastern and Southeastern Brazil achieved our objectives for all MPAs combined, they were poorly represented by no-take areas. These results reflect the bias

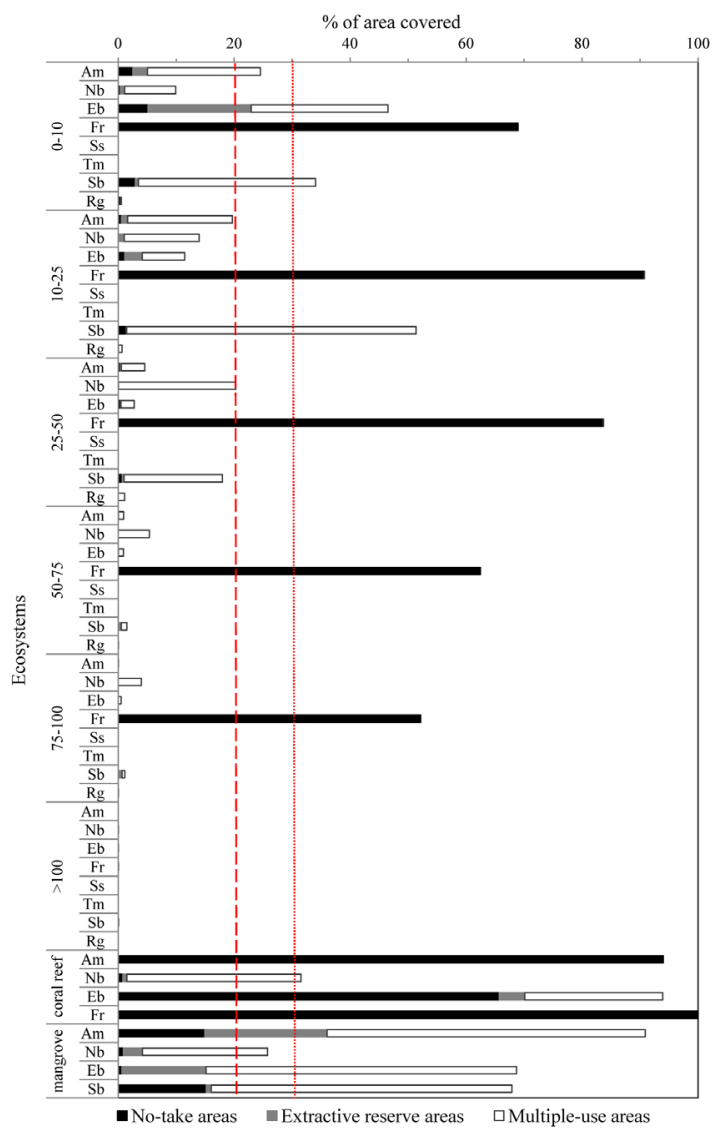

Figure 2. Percentage of each ecosystem covered by the three types of MPAs. Abbreviations for ecoregions: Am=Amazon, $\mathrm{Nb}=$ Northeastern Brazil, Eb= Eastern Brazil, Fr= Fernando de Noronha and Atoll das Rocas, Ss= São Pedro and São Paulo Islands, $\mathrm{Tm}=$ Trindade and Martin Vaz Islands, $\mathrm{Sb}=$ Southeastern Brazil, Rg=Rio Grande. Thicker red dashed vertical line indicates our $20 \%$ objective for representation in no-take areas. The other vertical line indicates our $30 \%$ objective for all MPA categories. in distribution of MPA types. Several ecoregions such as Southeastern Brazil have large percentages within MPAs, dominated strongly by extensive multiple-use areas. Other ecoregions lack protection entirely (e.g. São Pedro and São Paulo Islands and Trindade and Martin Vaz Islands). The distribution of no-take areas followed a similar pattern to that of all types of MPAs combined, with two exceptions: Northeastern Brazil had an extremely small percentage under no-take protection relative to total MPA coverage, and Fernando de Noronha and Atoll das Rocas had a large percentage of no-take areas relative to all MPAs combined.

\section{Connectivity}

The connectivity objective was partially met. Almost half (47\%) of the no-take areas were above the minimum desirable size (Figure 3A). There were many small no-take areas $\left(<10 \mathrm{~km}^{2}\right)$ in the Southeastern Brazil ecoregion. In contrast, all no-take areas in the Amazon ecoregion were bigger than $10 \mathrm{~km}^{2}$. The sizes of no-take areas varied from $<0.02 \mathrm{~km}^{2}$ to $6,573 \mathrm{~km}^{2}$. For spacing, about half the no-take areas (51\%) achieved our objective (Figure 3B). Spacing between no-takes varied widely from less than $0.3 \mathrm{~km}$ to nearly $250 \mathrm{~km}$. Their spatial distribution showed a clear contrast: a cluster of no-take areas in the Southeastern Brazil ecoregion (where more than $70 \%$ of no-take areas were separated by less than $15 \mathrm{~km}$ ), while no-take areas in the Amazonn ecoregion were more widely spaced (all more than $15 \mathrm{~km}$ ).
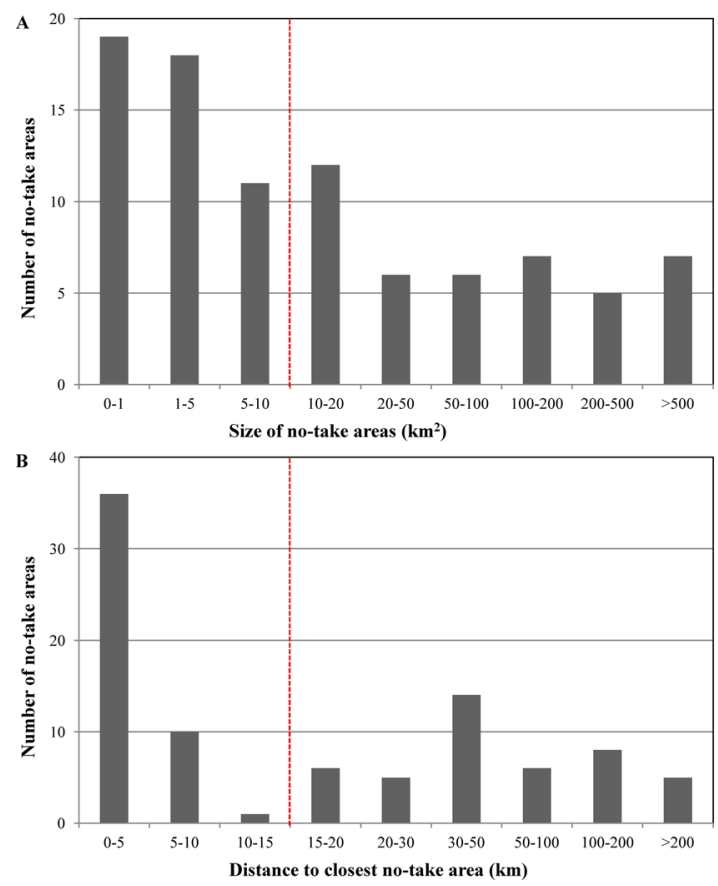

Figure 3. Distribution of size (A) and spacing (B) of Brazilian notake areas. The dashed vertical red lines indicate the objectives for size (A, at least $\left.10 \mathrm{~km}^{2}\right)$ and spacing (B, maximum $\left.15 \mathrm{~km}\right)$. 


\section{Risk spreading}

Only $23 \%$ of the ecosystems met the minimal number of replicates required by the risk-spreading objective (Figure 4). All ecosystems within the Southeastern Brazil ecoregion, except for those deeper than $75 \mathrm{~m}$, achieved this objective. This ecoregion had 44 no-take areas protecting different shallow ecosystems between 0 and 10 meters. A shared pattern was evident in the other ecoregions: the number of replicates of shallow ecosystems inside no-take zones outnumbered those of deeper ecosystems. Some ecoregions such as Rio Grande did not achieve the replication objective for any of its ecosystems. The mangrove ecosystems were the only ones to be protected in more than 3 different no-take areas across their range. For coral reefs, no-take areas failed to achieve the risk-spreading objective in all four ecoregions in which they occurred, mainly because they were covered by few relatively large no-take areas.

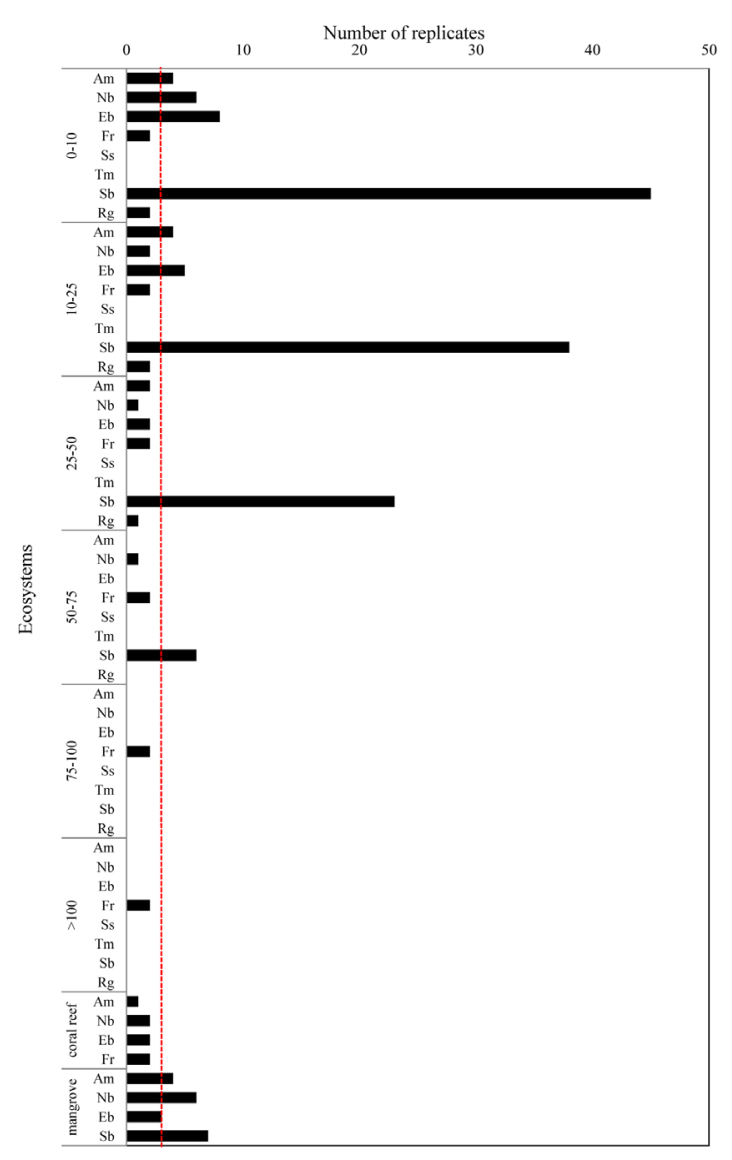

Figure 4. Number of replicates of each ecosystem within no-take areas. Abbreviations for ecoregional subdivisions: $\mathrm{Am}=\mathrm{Amazon}$, $\mathrm{Nb}=$ Northeastern Brazil, Eb $=$ Eastern Brazil, $\mathrm{Fr}=$ Fernando de Noronha and Atoll das Rocas, $\mathrm{Ss}=$ São Pedro and São Paulo Islands, $\mathrm{Tm}=$ Trindade and Martin Vaz Islands, $\mathrm{Sb}=$ Southeastern Brazil, Rg=Rio Grande. Red dashed vertical line indicates our conservation objective for replication.

\section{Discussion}

There is an urgent need for an increased effort to manage and protect the marine environment in Brazil to ensure its sustainability and persistence. Currently, the protection of the marine environment in Brazil is poor with less than $1.9 \%$ of the marine jurisdiction within MPAs and $0.14 \%$ within no-take areas. These figures update a recent estimate of MPA coverage from the Brazilian government (1.6\% of EEZ under protection; Brasil 2010) and highlight that formal management of marine resources in Brazil is in its initial stage. This percentage coverage is much lower than the $10 \%$ national objective and the $30 \%$ best-practice recommendation for all types of MPAs (Beck \& Odaya 2001; Fernandes et al. 2005; Svancara et al. 2005). An examination of the chronological pattern of creation of MPAs in Brazil (see Figure S3) revealed a slow rate of addition to the MPA system during the last 15 years, with only about $20 \%$ of total extent added during this period. If the rate since first establishment of an MPA creation is maintained, it will take another 25 years to achieve even the minimal Aichi target of $10 \%$ coverage of coastal and marine ecosystems to which the government is committed.

The spatial and geographic attributes of MPAs in Brazil are distinctly biased across ecosystems and ecoregions. Protection ranged from $0 \%$ to $100 \%$, with 41 of 56 ecosystems still below the $30 \%$ level for all MPA categories. While the number of MPAs in Brazil is quite limited, the current spatial configuration of MPAs reflects findings from gap analyses in other regions (see Spalding et al. 2008), especially from Latin America (e.g. Guarderas et al. 2008). Around the world, systems of MPAs are arguably biased towards areas with considerable knowledge of the status of marine systems, least use of marine resources, and greater interest by organizations (Guarderas et al. 2008; Weeks et al. 2010). Therefore, the need for a shift of techniques and features of interest when planning new MPAs has still to be fully recognized if marine conservation is to be effective.

Determining optimum MPA size and spacing to ensure persistence requires biological information that is currently unavailable. Although $47 \%$ of the Brazilian no-take areas had the minimum size required to maintain connectivity and more than half the Brazilian no-take areas were closely spaced (Halpern \& Warner 2003; Green et al. 2009), the overall system of MPAs cannot be considered well-connected. The current distribution of distances between no-take areas is not likely to encompass the dispersal distances of all species (Halpern \& Warner 2003; Shanks et al. 2003). Additionally, most ecosystem types (77\%) did not meet our risk spreading objective so existing MPA configuration is not contributing as a general strategy to ensure persistence with the aim of preventing the effects of disturbances on ecosystems (Álvarez-Romero et al. 2011). Our rules for spatial design presented here should be tailored to regionspecific connectivity requirements, which vary according to species composition, hydrodynamics, and disturbance 
history. To ensure viability of biological assemblages in the long term, spatial configuration of MPAs also needs to be complemented by their placement relative to features in the seascape that accumulate larvae, function as migratory pathways, and increase resilience against disturbances.

Without urgent action to protect Brazil's coastal and offshore waters, the dire situation of serious impacts is likely to worsen with rapidly expanding and intensifying fishing pressure (Araújo \& Martins 2009), pollution, conversion of coastal ecosystems to agricultural and urban areas (Copertino 2011), coastal development, and offshore mining and oil extraction (Da Silva et al. 1997). Importantly, a systematic approach is needed to counteract the emerging trend of MPAs being placed where they are most expedient politically but also least effective in mitigating threats to the marine environment (CBD 2013). Future research needs to carefully evaluate the extent to which placement of Brazilian MPAs is shaped by economic or social pressures. Both systematic additions to the Brazilian MPA system and improvement of data on marine biodiversity can proceed in parallel. Our study has shown that a coarse ecosystem delineation can provide helpful initial guidance for MPA design, but further delineation of ecosystems is desirable to more effectively account for spatial variations in marine biodiversity. As additional data are collected, subsequent gap analyses will yield further insights.

Further improvements to assessing protection status of marine ecosystems and species in Brazil are necessary. One way forward is to gather additional data that better represent the compositional patterns and key processes of marine biodiversity such as patch dynamics, oceanographic phenomena, and migration patterns (Pressey et al. 2007; Grantham et al. 2011). This would allow refined quantitative objectives, building on the beginnings presented in our study, for representation and persistence that reflect need for protection of features from current and emerging threats (Pressey et al. 2007). However, to date, knowledge of Brazilian marine biodiversity is poor and uneven (Amaral \& Jablonski 2005), so conservation objectives are likewise constrained. Regardless, investment in marine protection should not be delayed until better data are collected (Pressey \& Cowling 2001). Moreover, data on how well MPAs along Brazilian coast are managed or implemented are lacking (see Spalding et al. 2008). Financial shortage and poor inter-institutional coordination of coastal and ocean governance have hampered effective implementation and management of MPAs in Brazil (Gerhardinger et al. 2011). Consequently, our study is likely overestimating existing marine protection. If the effectiveness of protected areas were taken into account, the results would definitely be even worse.

Increasing the protection of the marine environment in Brazil is critical, not only to achieve government commitments but also to ensure marine resources are sustained through time. Effective conservation will only be attained by emphasizing relevant ecological criteria and explicit objectives to select additional MPAs. Future research is needed to identify better surrogates for marine biodiversity, more appropriate objectives for representation and persistence, and processes threatening marine biodiversity and ecosystem services. Local ecological knowledge of fishermen is a valuable asset for management plans; such knowledge provides both a detailed historical perspective of fisheries but also encourages stakeholder participation in planning, imperative for the success of implementation. Given limited knowledge of the Brazilian marine ecoregions, a participatory and adaptive approach is likely to lead to the best outcomes for conservation and sustainable use.

\section{Acknowledgements}

RAM acknowledges CNPq for financial support. MF and MM were supported by fellowships through the Australian Research Council Super Science Scheme. RAM, MF and RLP acknowledge the support of the Australian Research Council Centre of Excellence for Coral Reef Studies.

\section{References}

Airamé S et al., 2003. Applying ecological criteria to marine reserve design: a case study from the California Channel Island. Ecological Applications, 13:S170-S184. http://dx.doi. org/10.1890/1051-0761(2003)013[0170:AECTMR]2.0.CO;2

Allison GW et al., 2003. Ensuring persistence of marine reserves: catastrophes require adopting an insurance factor. Ecological Applications, 13:S8-S24. http://dx.doi. org/10.1890/1051-0761(2003)013[0008:EPOMRC]2.0.CO;2

Almany GR et al., 2009. Connectivity, biodiversity conservation and the design of marine reserve networks for coral reefs. Coral Reefs, 28:339-351. http://dx.doi.org/10.1007/ s00338-009-0484-x

Álvarez-Romero JG et al., 2011. Integrated land-sea conservation planning: the missing links. Annual Review of Ecology, Evolution, and Systematics, 42:381-409. http://dx.doi. org/10.1146/annurev-ecolsys-102209-144702

Amaral ACZ \& Jablonski S, 2005. Conservation of marine and coastal biodiversity in Brazil. Conservation Biology, 19:625631. http://dx.doi.org/10.1111/j.1523-1739.2005.00692.x

Araújo JN \& Martins AS, 2009. Aspects of the population biology of Cephalopholis fulva from the central coast of Brazil. Journal of Applied Ichthyology, 25:328-334. http:// dx.doi.org/10.1111/j.1439-0426.2008.01181.x

Ban NC et al., 2012. Conservation objectives and sea-surface temperature anomalies in the Great Barrier Reef. Conservation Biology, 26:799-809. http://dx.doi. org/10.1111/j.1523-1739.2012.01894.x

Beck MW \& Odaya M, 2001. Ecoregional planning in marine environments: identifying priority sites for conservation in the northern Gulf of Mexico. Aquatic Conservation-Marine and Freshwater Ecosystems, 11(4):235-242. http://dx.doi. org/10.1002/aqc.449

Brasil. Ministério do Meio Ambiente - MMA, 2010. Panorama da conservação dos ecossistemas costeiros e marinhos no Brasil. Brasília. 
Brasil. Presidência da República, 2000. Lei no 9.985, de 18 de julho de 2000. Diário Oficial da República Federativa do Brasil, Brasília, jul.

Brasil. Presidência da República, 2006. Decreto no 5.758, de 13 de abril de 2006. Diário Oficial da República Federativa do Brasil, Brasília, abr.

Convention on Biological Diversity - CBD, 2013. Quick guide to the Aichi Biodiversity Targets: protected areas increased and improved. Available from: <www.cbd.int/ doc/strategic-plan/targets/T11-quick-guide-en.pdf $>$.

Copertino MS, 2011. Add coastal vegetation to the climate critical list. Nature, 473:255-255. http://dx.doi.org/10.1038/473255a

Da Silva EM et al., 1997. Impact of petroleum pollution on aquatic coastal ecosystems in Brazil. Environmental Toxicology and Chemistry, 16:112-118. http://dx.doi.org/10.1002/ etc. 5620160112

Fernandes L et al., 2005. Establishing representative no-take areas in the Great Barrier Reef: large-scale implementation of theory on marine protected areas. Conservation Biology, 19:17331744. http://dx.doi.org/10.1111/j.1523-1739.2005.00302.x

Gerhardinger LC et al., 2011. Marine protected dramas: The flaws of the Brazilian National System of Marine Protected Areas. Environmental management, 47:630-643. http:// dx.doi.org/10.1007/s00267-010-9554-7

Grantham et al. 2011. Accommodating dynamic oceanographic processes and pelagic biodiversity in marine conservation planning. Plos One, 6:1-16. http://dx.doi.org/10.1371/ journal.pone.0016552

Green A et al., 2009. Designing a resilient network of marine protected areas for Kimbe Bay, Papua New Guinea. Oryx, 43:488-498. http://dx.doi.org/10.1017/S0030605309990342

Guarderas AP et al., 2008. Current status of marine protected areas in Latin America and the Caribbean. Conservation Biology, 22:1523-1739. http://dx.doi. org/10.1111/j.1523-1739.2008.01023.x

Halpern BS et al., 2008. A global map of human impact on marine ecosystems. Science, 319: 948-952. http://dx.doi. org/10.1126/science.1149345

Halpern BS et al., 2012. An index to assess the health and benefits of the global ocean. Nature, 488:615-620. http:// dx.doi.org/10.1126/science.1149345

Halpern BS \& Warner RR, 2003. Matching marine reserve design to reserve objectives. Proceeding of the Royal Society London, 270:1871-1878. http://dx.doi.org/10.1098/rspb.2003.2405

Harris PT \& Whiteway T, 2009. High seas marine protected areas: Benthic environmental conservation priorities from a GIS analysis of global ocean biophysical data. Ocean \& Coastal Management, 52:22-38. http://dx.doi.org/10.1016/j. ocecoaman.2008.09.009

Kramer DL \& Chapman MR, 1999. Implications of fish home range size and relocation for marine reserve function. Environmental Biology of Fishes, 55:65-79. http://dx.doi. org/10.1023/A:1007481206399

Leão, ZMAN \& Dominguez JML, 2000. Tropical coast of Brazil. Marine Pollution Bulletin, 41:112-122. http://dx.doi. org/10.1016/S0025-326X(00)00105-3
Lombard AT et al., 2007. Conserving pattern and process in the southern ocean: designing a marine protected area for the Prince Edward Islands. Antartic Science, 19:39-54. http://dx.doi.org/10.1017/S0954102007000077

Metcalfe K et al., 2013. Impacts of data quality on the setting of conservation planning targets using the species-area relationship. Diversity and Distributions, 19:1-13. http:// dx.doi.org/10.1111/j.1472-4642.2012.00921.x

Mills $\mathrm{M}$ et al., 2011. Incorporating effectiveness of communitybased management in a national marine gap analysis for Fiji. Conservation biology, 25:1155-1164. http://dx.doi. org/10.1111/j.1523-1739.2011.01749.x

Pressey RL \& Cowling RM, 2001. Reserve selection algorithms and the real world. Conservation Biology, 15:275-277.

Pressey RL et al., 2003. Formulating conservation targets for biodiversity pattern and process in the Cape Floristic Region, South Africa. Biological Conservation, 112:99-127. http:// dx.doi.org/10.1016/S0006-3207(02)00424-X

Pressey RL et al., 2007. Conservation planning in a changing world. Trends in ecology \& evolution, 22:583-592. http:// dx.doi.org/10.1016/j.tree.2007.10.001

Roberts CM et al., 2003. Ecological criteria for evaluating candidate sites for marine reserves. Ecological Applications, 13:199-214. http://dx.doi. org/10.1890/1051-0761(2003)013[0199:ECFECS]2.0.CO;2

Rodrigues ASL et al., 2004. Global gap analysis: priority regions for expanding the blobal protected-area network. Bioscience, 54:1092-1100. http://dx.doi. org/10.1641/0006-3568(2004)054[1092:GGAPRF]2.0.CO;2

Rondinini C \& Chiozza F, 2010. Quantitative methods for defining percentage area targets for habitat types in conservation planning. Biological Conservation, 143:16461653. http://dx.doi.org/10.1016/j.biocon.2010.03.037

Shanks AL et al., 2003. Propagule dispersal distance and the size and spacing of marine reserves. Ecological Applications, 13:S159-S169. http://dx.doi. org/10.1890/1051-0761(2003)013[0159:PDDATS]2.0.CO;2

Spalding MD et al., 2008. Toward representative protection of the world's coasts and oceans-progress, gaps, and opportunities. Conservation Letters, 1:217-226. http:// dx.doi.org/10.1111/j.1755-263X.2008.00030.x

Svancara LK et al., 2005. Policy-driven versus evidencebased conservation: a review of political targets and biological needs. BioScience, 55:989-995. http://dx.doi. org/10.1641/0006-3568(2005)055[0989:PVECAR]2.0.CO;2

Weeks R et al., 2010. Effectiveness of marine protected areas in the Philippines for biodiversity conservation. Conservation biology, 24:531-540. http://dx.doi. org/10.1111/j.1523-1739.2009.01340.x

Worm B et al., 2006. Impacts of biodiversity loss on ocean ecosystem services. Science, 314:787-790. http://dx.doi. org/10.1126/science.1132294

Received: April 2013

First Decision: May 2013

Accepted: June 2013 